\title{
Assessment of Hydrostatic Temperature Conditions Machine Plate Supports
}

\author{
Almokhammad A. Mokhammad, \\ Evgeny A. Sorokin and Maksim V. Brungardt* \\ Siberian Federal University \\ Krasnoyarsk, Russian Federation
}

Received 15.07.2019, received in revised form 09.08.2019, accepted 12.10.2019

Abstract. The working fluid temperature in the hydrostatic support system of the metal working machine plate is determined as a function of the drive operation time under different operating conditions. Temperature deformations of parts, units and assemblies of metal cutting machines are greatly influenced by the temperature of hydraulic drive working fluid, so the issues of optimization of working fluid temperature are given more attention.

Experimental studies of the operating fluid temperature of the hydraulic support system of the faceplate and parameters affecting its changes were carried out under conditions close to operational conditions. Parts of different mass (0.5-3.8 t) were processed at different speeds of plate rotation.

Keywords: metal cutting machine, plate support, hydraulic drive operating fluid temperature.

Citation: Mokhammad A.A., Sorokin E.A., Brungardt M.V. Assessment of hydrostatic temperature conditions machine plate supports, J. Sib. Fed. Univ. Eng. \& Technol., 2020, 13(1), 94-99. DOI: 10.17516/1999-494X-0188

\section{Оценка температурного режима гидростатических опор}

\section{планшайбы станка}

\author{
А.А. Мохаммад, Е.А. Сорокин, М.В. Брунгардт \\ Сибирский федеральный университет \\ Российская Федерачия, Красноярск
}

Аннотация. Определены зависимости температуры рабочей жидкости в системе гидростатических опор планшайбы металлообрабатывающего станка от времени работы привода в различных эксплуатационных условиях.

(C) Siberian Federal University. All rights reserved

This work is licensed under a Creative Commons Attribution-NonCommercial 4.0 International License (CC BY-NC 4.0).

* Corresponding author E-mail address: maxbrung@gmail.com 
Определены зависимости температуры рабочей жидкости в системе гидростатических опор планшайбы металлообрабатывающего станка от времени работы привода в различных эксплуатационных условиях. Рассмотрены возникающие деформации узлов и агрегатов станков от тепловых воздействий рабочей жидкости гидропривода. Экспериментально исследованы температуры рабочей жидкости в гидростатических опорах планшайбы при обработке заготовок от 0,5 до 3,5 т.

Ключевые слова: металлорежущий станок, опора планшайбы, температура рабочей жидкости гидропривода.

Цитирование: Мохаммад, А.А. Оценка температурного режима гидростатических опор планшайбы станка / А.А. Мохаммад, Е.А. Сорокин, М.В. Брунгардт // Журн. Сиб. федер. ун-та. Техника и технологии, 2020. 13(1). С. 94-99. DOI: $10.17516 / 1999-494 X-0188$

На температурные деформации деталей, узлов и агрегатов металлорежущих станков большое влияние оказывает температура рабочей жидкости гидропривода, поэтому вопросам оптимизации температуры рабочей жидкости уделяют большое внимание [1].

Экспериментальные исследования температуры рабочей жидкости системы гидростатических опор планшайбы и параметров, влияющих на ее изменения, проводили в условиях, близких к эксплуатационным. Производили обработку деталей различной массы (0,5-3,8 т) на разных скоростях вращения планшайбы.

Для измерений воздействующих параметров и параметров функций отклика применяли как штатные (установленные на станке), так и дополнительные средства измерения. Измерения проводили в течение 12 ч. В начале измерений (в начале рабочей смены) температура рабочей жидкости равнялась температуре окружающего воздуха. Показания манометрического термометра регистрировали визуально. Выносной датчик термометра, имеющий длину 500 мм, был опущен в гидравлический бак (рис. 1) через заливную горловину и находился примерно на одинаковом расстоянии от верхней и нижней стенок бака.

В начале исследований в баке вместимостью 250 л в качестве рабочей жидкости находилось масло индустриальное И-20 в объеме 200 л. Вязкость масла составляла 22 сСт при $50{ }^{\circ} \mathrm{C}$,

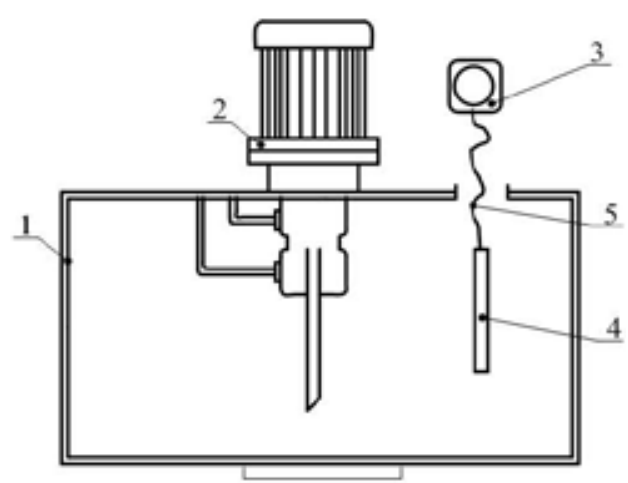

Рис. 1. Схема измерения температуры: 1 - бак; 2 - насосная установка; 3 - манометрический термометр; 4 - выносной датчик; 5 - гибкая соединительная трубка

Fig. 1. Scheme of measurement of temperature: 1 - tank; 2 - pumping plant; 3 - manometric thermometer; 4 portable sensor; 5 - flexible connecting tube 
плотность -885 кг/м³. По проведению всех необходимых замеров часть масла из бака была отобрана и добавлено масло И-40 для увеличения вязкости рабочей жидкости. После добавления вязкость масла составила 28 сСт при $50{ }^{\circ} \mathrm{C}$, плотность осталась прежней $-885 \pm 1$ кг/м.

Температура поверхности планшайбы регистрировалась одновременно с температурой рабочей жидкости для более точного определения разницы температур нижней части планшайбы, омываемой рабочей жидкостью, и верхней частью, рассеивающей тепло в окружающее пространство. При черновой обработке детали и низкой скорости вращения планшайбы температуру поверхности замеряли контактным термометром HD8464H “Borletti” непосредственно при вращении, а при чистовой обработке и, соответственно, большей скорости вращения, планшайбу приходилось останавливать и снова запускать после проведения замеров.

Величину гидростатической подушки (всплытие планшайбы) замеряли индикатором часового типа.

Скорость вращения планшайбы контролировали по индикации числового программного устройства "Bosch Alfa-2".

Изменению температуры рабочей жидкости системы гидростатических опор способствует изменение нескольких факторов. К таким факторам относятся: рабочее давление в системе, вязкость рабочей жидкости, масса обрабатываемой детали, скорость вращения планшайбы [2-5].

По результатам замеров параметров при проведении экспериментальных исследований были построены графики зависимостей температуры рабочей жидкости от вышеперечисленных факторов.

Зависимости, показанные на рис. 2, получены при скорости вращения планшайбы 6 об/мин, вязкости рабочей жидкости -22 сСт и массе обрабатываемой детали 3800 кг.

Зависимости на рис. 3 получены при рабочем давлении в системе 19 кг/см², вязкость рабочей жидкости 22 сСт, скорость вращения планшайбы 6 об/мин.

Зависимости на рис. 4 получены при рабочем давлении в системе 19 кг/см², скорость вращения планшайбы 6 об/мин, масса обрабатываемой детали 3800 кг.

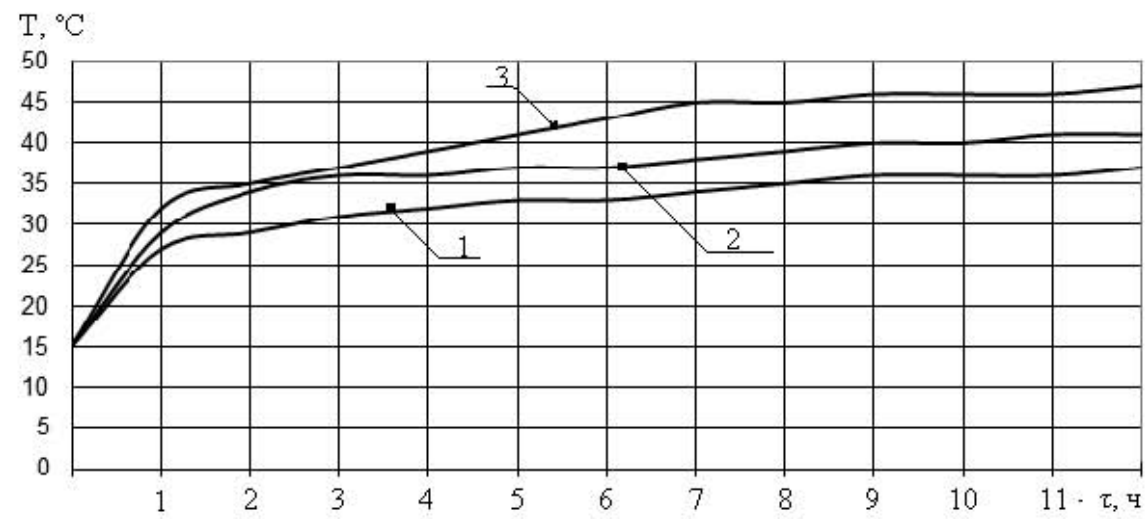

Рис. 2. График зависимости температуры рабочей жидкости от времени при различных значениях

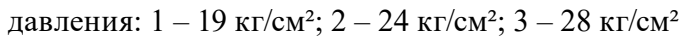

Fig. 2. The schedule of dependence of temperature of a hydraulic medium from time at various values of pressure: $1-19 \mathrm{~kg} / \mathrm{cm}^{2} ; 2-24 \mathrm{~kg} / \mathrm{cm}^{2} ; 3-28 \mathrm{~kg} / \mathrm{cm}^{2}$ 


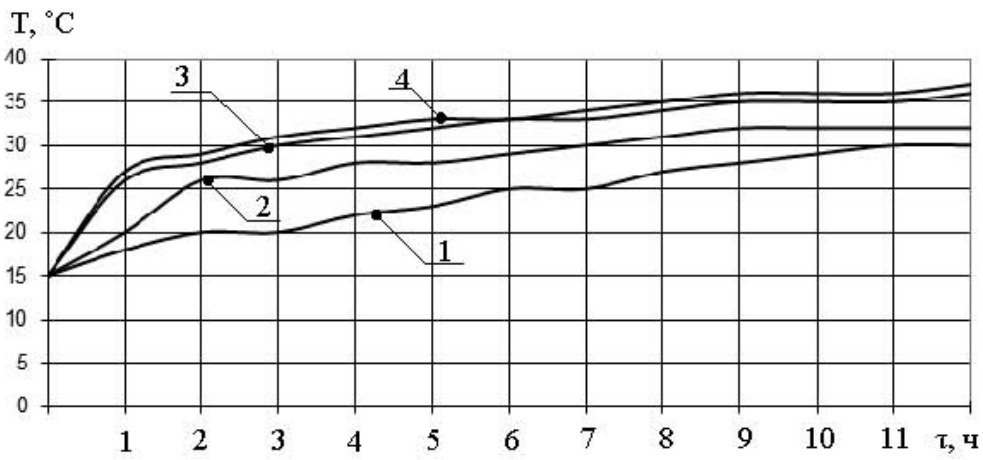

Рис. 3. График зависимости температуры рабочей жидкости от времени при различных значениях массы деталей: 1 - без детали; 2 - 500 кг; 3 - 2000 кг; 4 - 3800 кг

Fig. 3. The schedule of dependence of temperature of a hydraulic medium from time at various values of mass of details: 1 - the detail is absent; $2-500 \mathrm{~kg} ; 3-2000 \mathrm{~kg} ; 4-3800 \mathrm{~kg}$

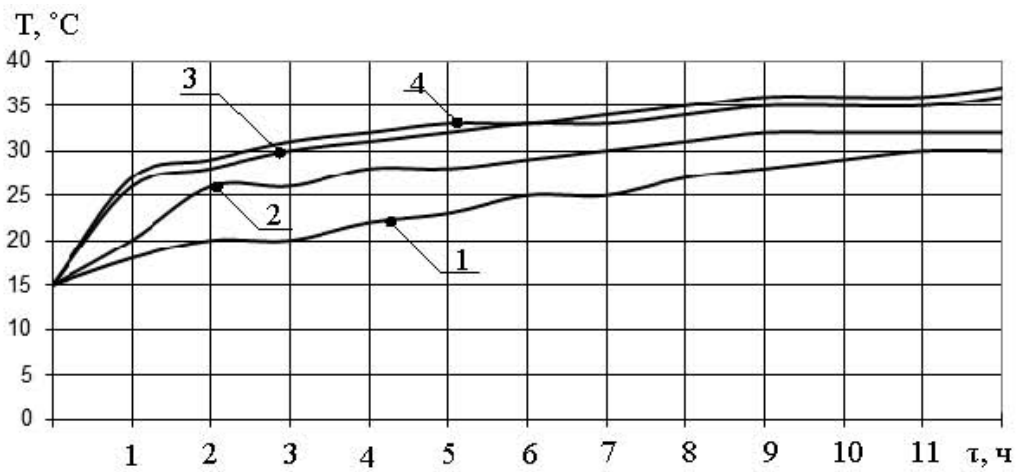

Рис. 4. График зависимости температуры рабочей жидкости от времени при различных значениях вязкости: 1 - без детали; 2 - 500 кг; 3 - 2000 кг; 4 - 3800 кг

Fig. 4. The schedule of dependence of temperature of a hydraulic medium from time at various values of viscosity: 1 - the detail is absent; $2-500 \mathrm{~kg} ; 3-2000 \mathrm{~kg} ; 4-3800 \mathrm{~kg}$

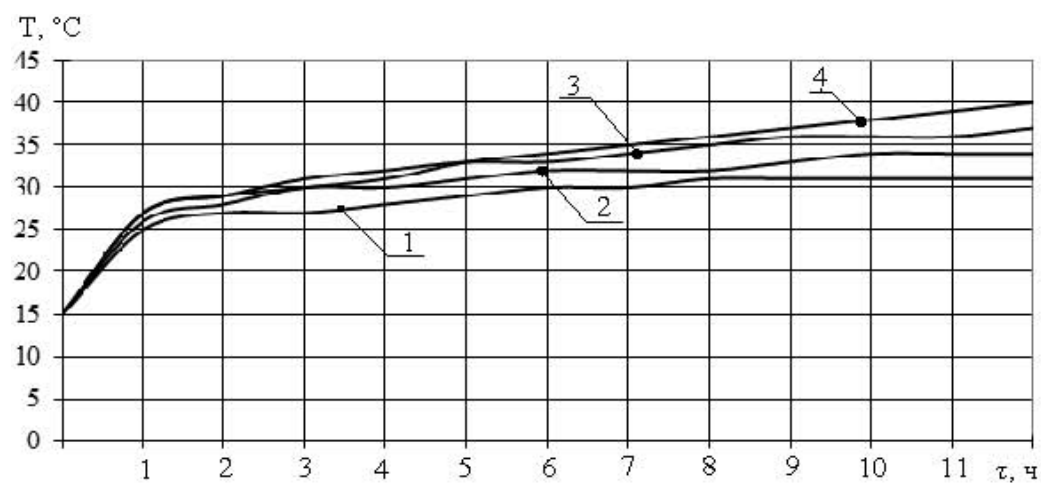

Рис. 5. График зависимости температуры рабочей жидкости от времени при различных числах оборотов планшайбы: 1 - 4 об/мин; 2 - 6 об/мин; 3 - 11 об/мин; 4 - 20 об/мин

Fig. 5. The schedule of dependence oaf temperature of a hydraulic medium from time at various ranges of speeds of the faceplate: $1-4 \mathrm{rpm} ; 2-6 \mathrm{rpm} ; 3-11 \mathrm{rpm} ; 4-20 \mathrm{rpm}$ 


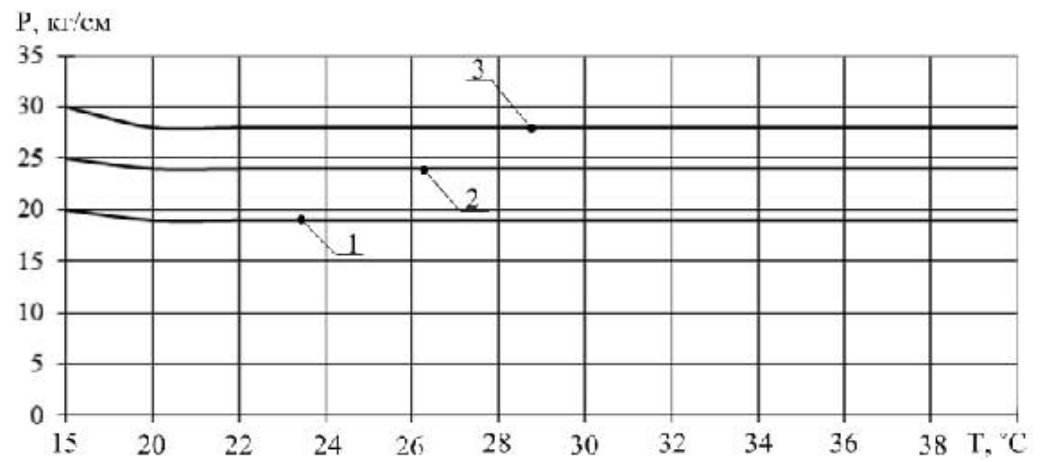

Рис. 6. График зависимости падения рабочего давления от температуры рабочей жидкости при различных

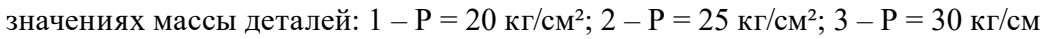

Fig. 6. The schedule of dependence of falling of working pressure on temperature of a hydraulic medium at various values of mass of details: $1-\mathrm{P}=20 \mathrm{~kg} / \mathrm{cm}^{2} ; 2-\mathrm{P}=25 \mathrm{~kg} / \mathrm{cm}^{2} ; 3-\mathrm{P}=30 \mathrm{~kg} / \mathrm{cm}^{2}$

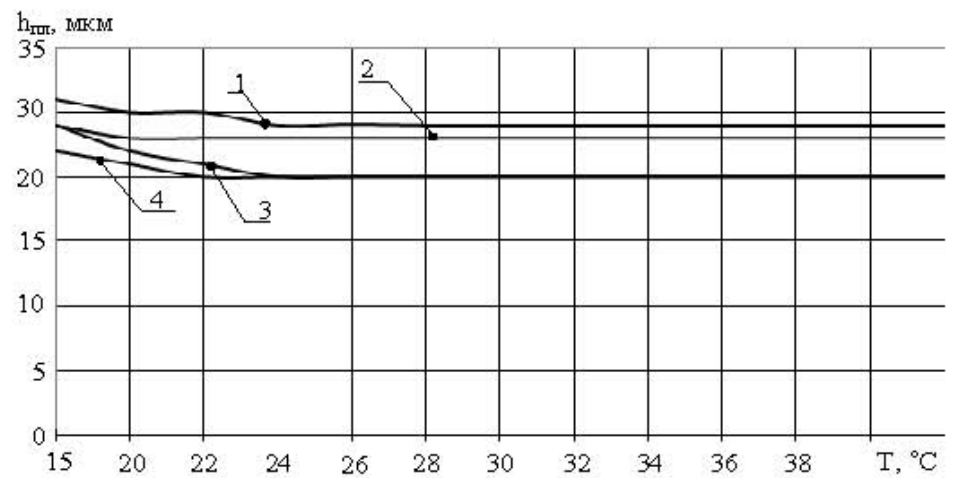

Рис. 7. График зависимости всплытия планшайбы от температуры рабочей жидкости: 1 - без детали; 2 500 кг; $3-2000$ кг; $4-3800$ кг

Fig. 7. Schedule of dependence of emersion of the faceplate on temperature of a hydraulic medium: 1 - without detail; $2-500 \mathrm{~kg} ; 3-2000 \mathrm{~kg} ; 4-3800 \mathrm{~kg}$

Во время черновой обработки детали частота вращения составляла 4 и 6 об/мин, а во время чистовой обработки - 11 и 20 об/мин соответственно (рис. 5). Масса обрабаты-

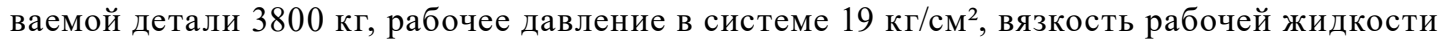
22 сСт.

Зависимости, показанные на рис. 6, получены при трех значениях давлений $-20,25$ и

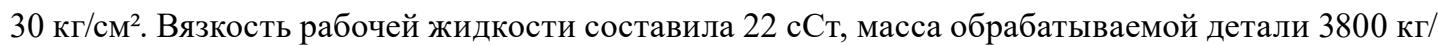
$\mathrm{cm}^{2}$, скорость вращения планшайбы 6 об/мин.

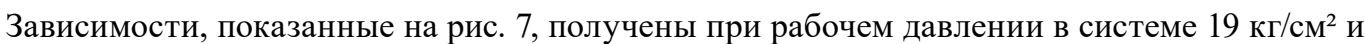
вязкости рабочей жидкости $22 \mathrm{cCт.}$

Анализ зависимостей, предоставленных на рис. 2-5, показывает, что температура рабочей жидкости существенно зависит от давления в системе и вязкости и в меньшей степени - от массы и скорости вращения планшайбы. 
Падение рабочего давления незначительно, происходит в первоначальный момент времени работы системы гидростатических опор и влияния на характер изменения температуры рабочей жидкости не оказывает. Температура рабочей жидкости также практически не влияет на величину всплытия планшайбы.

\section{Список литературы / References}

[1] Бушуев В.В., Цыпунов О.К. Тепловые явления в гидростатических опорах. Станки и инструмент, 1987, 11, 27-29 [Bushuev V.V., Cypunov O.K. Thermal phenomena in hydrostatic bearings, J. Machines and tool, 1987, 11, 27-29 (in Russian)]

[2] Бушуев В.В., Цыпунов О.К, Федоров А.И. Гидростатические шпиндельные опоры тяжелых расточных станков. Станки и инструмент, 1984, 12, $12-15$ [Bushuev V.V., Tsypunov O.K., Fyodorov A.I. Hydrostatic spindle bearings of heavy boring machines, J. Machines and tool, 1984, 12, 12-15 (in Russian)]

[3] Брунгардт М.В. и др. Численное исследование переходных процессов в самоустанавливающейся адаптивной гидростатической опоре. Технология машиностроения, 2016, 2, 49-53 [Brungardt M.V. et al. Numerical transient study in self-adjusting adaptive hydrostatic bearing, 2016, 2, 49-53 (in Russian)]

[4] Марусич К.В. Прогноз температурных перемещений станков, работающих в условиях переменных тепловых режимов. Обработка металлов (технология, оборудование, инструменmbl), 2011, 4, 74-77 [Marusich K.V. Forecast of temperature movements of machines operating under conditions of variable thermal conditions, Metal processing (technology, equipment, tools), 2011, 4, 74-77 (in Russian)] 